\title{
Obstetric care navigation: a new approach to promote respectful maternity care and overcome barriers to safe motherhood
}

\author{
Kirsten Austad ${ }^{1,2}$, Anita Chary ${ }^{1,3}$, Boris Martinez ${ }^{1}$, Michel Juarez ${ }^{1}$, Yolanda Juarez Martin¹, Enma Coyote Ixen ${ }^{1}$
} and Peter Rohloff ${ }^{1,4^{*}}$ (D)

\begin{abstract}
Background: Disrespectful and abusive maternity care is a common and pervasive problem that disproportionately impacts marginalized women. By making mothers less likely to agree to facility-based delivery, it contributes to the unacceptably high rates of maternal mortality in low- and middle-income countries. Few programmatic approaches have been proposed to address disrespectful and abusive maternity care.

Obstetric care navigation: Care navigation was pioneered by the field of oncology to improve health outcomes of vulnerable populations and promote patient autonomy by providing linkages across a fragmented care continuum. Here we describe the novel application of the care navigation model to emergency obstetric referrals to hospitals for complicated home births in rural Guatemala. Care navigators offer women accompaniment and labor support intended to improve the care experience-for both patients and providers - and to decrease opposition to hospital-level obstetric care. Specific roles include deflecting mistreatment from hospital staff, improving provider communication through language and cultural interpretation, advocating for patients' right to informed consent, and protecting patients' dignity during the birthing process. Care navigators are specifically chosen and trained to gain the trust and respect of patients, traditional midwives, and biomedical providers. We describe an ongoing obstetric care navigator pilot program employing rapid-cycle quality improvement methods to quickly identify implementation successes and failures. This approach empowers frontline health workers to problem solve in real time and ensures the program is highly adaptable to local needs.
\end{abstract}

Conclusion: Care navigation is a promising strategy to overcome the "humanistic barrier" to hospital delivery by mitigating disrespectful and abusive care. It offers a demand-side approach to undignified obstetric care that empowers the communities most impacted by the problem to lead the response. Results from an ongoing pilot program of obstetric care navigation will provide valuable feedback from patients on the impact of this approach and implementation lessons to facilitate replication in other settings.

Keywords: Maternal health, Respectful maternity care, Disrespect and abuse, Maternal mortality, Guatemala, Indigenous health, Quality improvement

\footnotetext{
* Correspondence: peter@wuqukawoq.org

'Wuqu' Kawoq | Maya Health Alliance 2 Calle 5-43, Zona 1, Santiago

Sacatepéquez, Guatemala

${ }^{4}$ Division of Global Health Equity, Brigham and Women's Hospital, 75 Francis

Street, Boston, MA 02115, USA

Full list of author information is available at the end of the article
} 


\section{Introduction}

While maternal mortality has declined by $44 \%$ globally from 1990 to 2015, disparities persist [1]. Poor and otherwise marginalized women continue to face the highest risk of death from largely preventable complications of pregnancy and childbirth. Promoting facility-based delivery with a skilled birth attendant for all women is a key strategy to reduce this disparity $[2,3]$. Large-scale global interventions to date have included educating mothers and other stakeholders regarding the benefits of facility-based delivery and decreasing transportation barriers. Despite these efforts, over half of women worldwide still deliver at home with an unskilled birth attendant [1], a fact that signals the need to understand and address persistent barriers that women face.

A strong body of literature demonstrates that dissatisfaction with maternity care is an important deterrent to facility-based births [4, 5]. Disrespectful and abusive treatment of women seeking obstetric care appears to be widespread and pervasive. According to the framework established by Bowser \& Hill [6], it includes not only verbal and physical abuse, but also mistreatment such as discrimination, non-consented clinical care, denial of care, and detention in health facilities for failure to pay $[7,8]$. These transgressions are important not only because they deter women from skilled delivery, but also because they are direct human rights violations that take place within the very medical establishments charged with helping women achieve "the right to the highest attainable standard of health" [9].

Disrespectful maternity care is not merely an interpersonal problem, but, rather, is driven by health system structures and social norms [10, 11]. Most system-level deficiencies lie outside of the control of individual providers. These include hospital overcrowding, inadequate resources, understaffing, and mistreatment of hospital workers themselves [12]. Such institutional factors promote provider burnout and non-empathic care. In addition, social inequalities tend to exist between patients receiving care in public hospitals and the providers caring for them. Providers' deeply held, often unconscious biases based on race, class, and gender can lead to discrimination towards patients [11, 12].

The World Health Organization acknowledges that disrespectful care is "a powerful disincentive for women to seek and use maternal health care services." [4] However, interventions to eliminate or mitigate abuse and mistreatment women in birthing facilities have to date been limited in both number and scope. Promising work in Tanzania [13] and Kenya [14] have implemented hospital staff training-including facilitated reflection on the motivators of unprofessional behavior of health workers-and shown improvements in respectful care.
In this article we respond to a recent call [15] for innovative approaches to promote respectful maternity care by presenting our model: obstetric care navigation. This approach trains lay women to facilitate referrals from home births to hospitals when complications arise, improving patient experience through accompaniment, translation, and labor support while simultaneously overcoming other barriers such as transportation. In this commentary, we explore the multifaceted role that care navigators play in facilitating higher quality respectful woman-centered care.

\section{Maternal heath in rural Guatemala}

Recently, Guatemala was chosen as one of three global sites for an in-depth study of disrespectful and abusive maternity care [16]. This reflects the fact that this small Central American nation presents one of the most challenging landscapes for maternal health in the world. Although Guatemala's overall maternal mortality rate (MMR) is 88 per 100,000 , rates among indigenous Guatemalans, mostly of Maya descent, may be twice this high $[1,17]$.

Many factors contribute to this disparity. While indigenous Guatemalans represent at least $45 \%$ of the overall population [18], they control little of the country's wealth and land rights [19]. A civil war that took place from 1960 to 1996 included state-sponsored killing of an estimated 300,000 Maya people [20]. Twenty years after the war, stark inequalities in healthcare for indigenous persons persist. Although free medical care, including prenatal care, is constitutionally guaranteed to all Guatemalan women through Ministry of Health facilities [21, 22], chronic underfunding, allegations of corruption, inadequate staffing, frequent medication stock-outs, and long wait times all contribute to low-quality care [23]. Furthermore, while about half of indigenous Guatemalans speak primarily a Mayan language [24], public services are available only in Spanish. Transportation also limits access to emergent facility-care, as most indigenous Guatemalans live in rural areas located far from hospitals [18].

In this context, over half of Maya women forgo institutional delivery and give birth at home with traditional midwives [18]. These "unskilled" attendants receive basic training from the Ministry of Health and integrate it with traditional practices [25]. When complications arise, traditional midwives are trained to refer patients to public facilities for obstetric care, but many women refuse or delay care [26]. Many especially fear hospital delivery, specifically citing unconsented sterilization as a factor [26]. In a recent study, three factors were strongly associated with a positive hospital birth experience: if the patient felt she was treated with respect by staff, if she was allowed accompaniment during labor, and if she was spoken to in her indigenous language [27]. 
While these rights are guaranteed by Guatemalan law, in practice they are rarely granted.

The concept of obstetric care navigation was born out of a collaboration between traditional midwives serving rural indigenous communities of the central Guatemalan highlands and Wuqu' Kawoq | Maya Health Alliance (MHA), a non-governmental primary care organization in these same communities. This built on an earlier project to empower traditional midwives with better tools to detect preeclampsia in the community setting $[28,29]$. In this project, detection at times did not translate into improved health outcomes because patients frequently refused to leave their communities for hospital care. It became clear to us that a new paradigm for facilitating referral care was needed.

\section{Care navigation: A brief history}

Care navigators were first used to address the difficulties low-income minority patients in the United States faced in receiving timely cancer screening and treatment [30]. The original architects of care navigation programs witnessed how marginalized patients inordinately struggled to traverse the fragmented cancer care continuum [31]. Poor communication between patients and their doctors and barriers arising from limited economic resources, fear, and distrust exacerbated this challenge. In response, care navigators were trained to coordinate services (from community-based screening through cancer treatment) to help patients seamlessly flow through the disjointed health system. Care navigators develop one-on-one relationships with patients and provide motivation and emotional support, features that are shared with the patient accompaniment model popularized in global health for improving adherence to tuberculosis and HIV/AIDS treatment [32-35]. Care navigators have been shown to lessen delays in cancer diagnosis and treatment that contribute to poor outcomes and racial disparities [31, 36]. The model has since been adapted to improve chronic disease care, with some promising evidence of benefit in patients with limited English proficiency in the United States [37].

Over the past decade, MHA has developed a care navigation program to facilitate timely cancer care for Maya patients within Guatemala's public hospitals [38]. Due to health system fragmentation and high out-of-pocketcosts, many poor or indigenous patients who present to the national cancer hospital do not complete treatment. For example, in a recent study of women with cervical cancer, only $35 \%$ of patients completed 5 -year treatment plans due to loss-to-follow-up [39]. However, with the help of care navigators from MHA's complex care navigation program, many patients have successfully completed cancer treatment, and the program has now expanded to serve a wider variety of patients with chronic diseases, such as end-stage renal disease and congenital heart disease [38].

\section{Obstetric care navigation}

Based on these preliminary experiences, we reasoned that a similar, carefully optimized care navigation model might also improve obstetric care. Therefore, in March 2017, we began a pilot program that employs care navigators to bridge the disjointed continuum of obstetric care from home delivery to hospital care. We devote the remainder of this commentary to describing the philosophy and design process for this program. We believe the approach may improve maternal and neonatal outcomes by preventing and mitigating disrespectful and abusive care in public hospitals and increasing rate of acceptance of medically-indicated referrals (Fig. 1). To our knowledge, no such program has ever been tested, though others have offered accompaniment at isolated points in the care continuum [40-42]. The pilot serves approximately 800 pregnant women/year from rural Maya communities in the central Guatemalan province of Chimaltenango. All women receive obstetric services from one of 45 collaborating traditional midwives, all of whom are credentialed through the Ministry of Health.

Participating midwives all are equipped with smart phones with a previously described decision support interface $[28,29]$ to communicate with the MHA clinical team when pregnancy and birth emergencies arise, ranging from the detection of preeclampsia during prenatal care to postpartum hemorrhage. The emergency line is staffed at all times by MHA health workers who-guided by simple clinical algorithms-support midwives' decision making on whether to refer. When emergency referral is indicated, an on-call care navigator is notified. She then works with the midwife and patient's family to arrange transport for the patient to the public hospital. If ambulance transport is not an option-a common occurrence in remote villages-a network of community members with vehicles is tapped to provide emergency transport.

Inside the hospital, care navigators provide a variety of services to improve quality of care and patient experience. Care navigators provide concrete assistance at all steps of the medical evaluation, such as translating between the Mayan languages spoken by most indigenous patients and Spanish-speaking nurses and physicians. As patients often find the hospital environment confusing and frightening, care navigators educate on expectations for the hospital experience, including information to explain or contextualize staff behaviors, brief clinical interactions, prolonged wait times, or visitation policies. They also provide updates for the patient's family and traditional midwife. Obstetric care navigators are given small budgets to facilitate purchase of medications, supplies, or laboratory testing requested by the medical team but not available in public hospitals due 


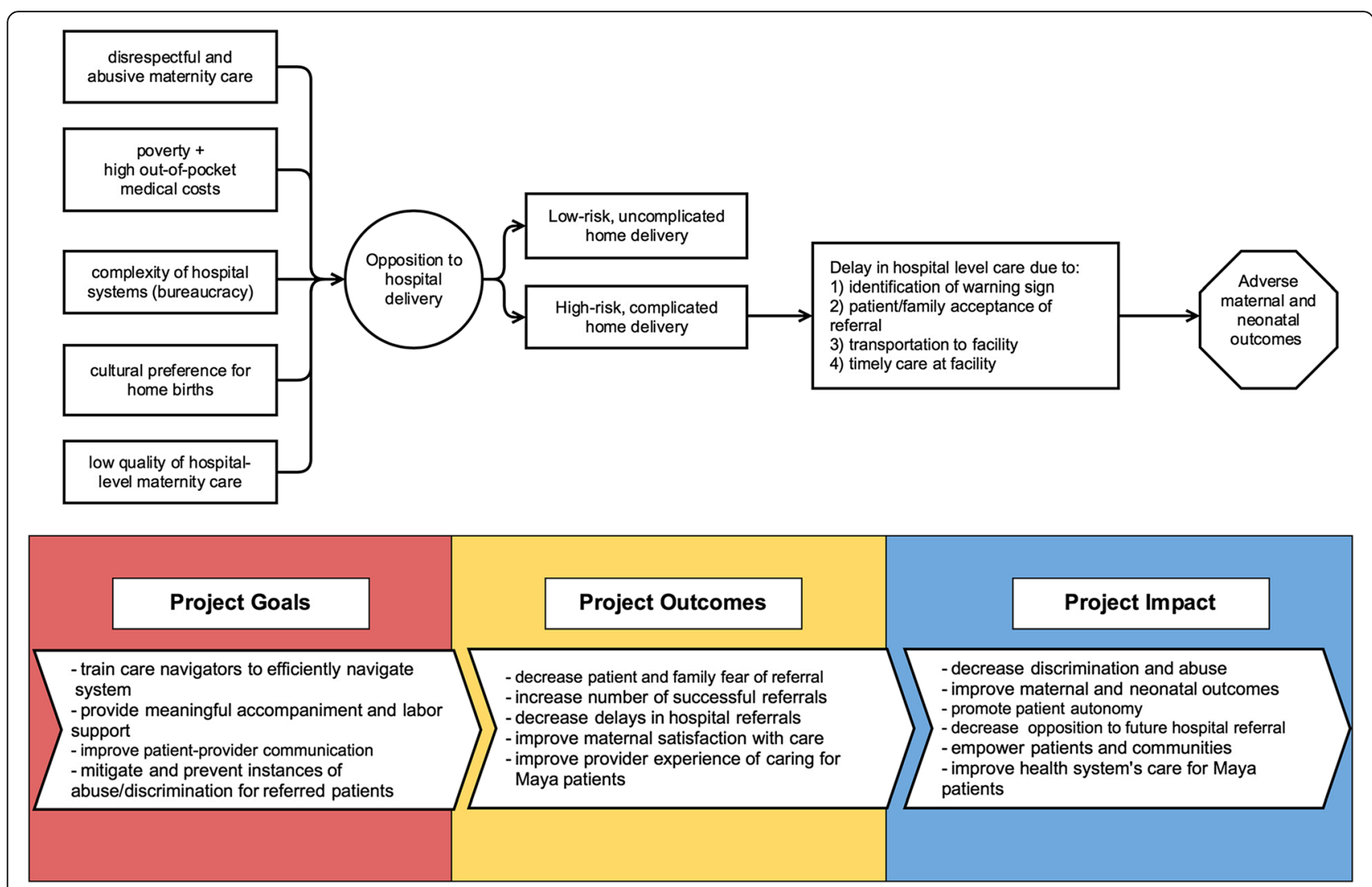

Fig. 1 Theoretical model for obstetric care navigator program

to stocks outs. They can also use funds to purchase small comforts for the patient and her family, such as snacks or arrange for family accommodation.

During births, obstetric care navigators enter labor wards to assist women with position change (including traditional standing delivery), breathing techniques, and supportive coaching in Mayan languages. In the case of caesarean delivery, they are present in the operating room to offer emotional support. Once her patient is discharged or comfortably resting postpartum, obstetric care navigators return home. Depending on each patient's individual needs care navigators may return to help facilitate hospital discharge, coordinate follow up, purchase medications, or even respond to a postpartum emergency that arises.

The pilot implementation team consists of a supervising doctor, nurse manager, field nurse, two community health workers, three care navigators, and collaborating midwives. Implementation is guided by the rapid-cycle quality improvement (RCQI) approach [43], including decisions about resource allocation and capacity for increasing volume of referrals. The leadership group includes the care navigators-drawn from the communities served by the project-and two elected midwives to represent these important perspectives. They meet every 2 weeks to review data on important performance indicators-such as referral volume and time to referral completion-in addition to qualitative feedback. This approach allows the team to quickly identify obstacles to referrals, empower frontline health workers to develop innovate solutions to implement on a small scale, and use data to assess effectiveness of these reforms. Care navigators' compensation is tied to referral volume, including additional incentives for successful referrals. This is part of the larger effort to promote an outcomes-driven approach, to ensure efficient use of donor funds, and to titrate referral volume to budget capacity.

\section{Potential impact on disrespectful and abusive maternity care} We believe that obstetric care navigators hold the potential to improve the hospital experience for patients. Beyond the obvious practical services they provide, they also have the potential to address humanistic barriers to facility-based delivery by preventing disrespectful care through multiple mechanisms (Table 1). First, their presence as observers can deter mistreatment, enhanced by the collegial relationships they form with hospital staff over time. Second, their role as interpreters improves patient-provider communication and helps patients exercise autonomy, which includes ensuring that providers obtain 
Table 1 Types of disrespectful and abusive care as categorized by Bohren and colleagues in their systematic review [5]. Each is paired with the systems-level drivers of this care (Propagating Factors) and specific supports that care navigators can provide in order to address them (Care Navigator Roles)

\begin{tabular}{|c|c|c|}
\hline Type & Propagating Factors & Care Navigator Roles \\
\hline $\begin{array}{l}\text { 1) Physical, sexual, or verbal } \\
\text { abuse }\end{array}$ & $\begin{array}{l}\text { Normalization of patient abuse } \\
\text { Role modeling of behaviors by superiors }\end{array}$ & $\begin{array}{l}\text { Mitigate through emotional support } \\
\text { Deter through mediation }\end{array}$ \\
\hline 2) Discrimination & $\begin{array}{l}\text { Social inequalities and segregation } \\
\text { Lack of consequences and oversight for } \\
\text { discriminatory treatment }\end{array}$ & $\begin{array}{l}\text { Advocate for incorporation of traditional birthing practices } \\
\text { Use cultural capital to identify both with patients and } \\
\text { providers }\end{array}$ \\
\hline $\begin{array}{l}\text { 3) Failure to provide professional } \\
\text { standard of care (including } \\
\text { patient's autonomy) }\end{array}$ & $\begin{array}{l}\text { Medical paternalism } \\
\text { High patient volume } \\
\text { Hierarchy of hospital staff } \\
\text { Lack of mechanisms to measure and } \\
\text { improve quality of care }\end{array}$ & $\begin{array}{l}\text { Advocate for appropriate and timely care } \\
\text { Assist providers in obtaining patient consent } \\
\text { Take steps to protect patients' dignity (ex: shielding } \\
\text { while changing into gown in public exam room) } \\
\text { Educate patients and hospital staff on mothers' rights }\end{array}$ \\
\hline 4) Poor communication & $\begin{array}{l}\text { Language barriers } \\
\text { Lack of training on effective } \\
\text { communication }\end{array}$ & $\begin{array}{l}\text { Translate between patients and providers } \\
\text { Report back to family and traditional midwife }\end{array}$ \\
\hline 5) Poor rapport & $\begin{array}{l}\text { Social stratification } \\
\text { Burnout-motivated behaviors }\end{array}$ & $\begin{array}{l}\text { Act as cultural broker } \\
\text { Provide emotional and labor support }\end{array}$ \\
\hline 7) Health system constraints & $\begin{array}{l}\text { Provider frustration due to lack of resources Lack of } \\
\text { basic resources to provide care } \\
\text { Uncomfortable } \\
\text { working conditions }\end{array}$ & $\begin{array}{l}\text { Provide economic support for medical needs } \\
\text { Contextualize limitations faced by medical providers for } \\
\text { patients and family }\end{array}$ \\
\hline 8) Health system conditions & Excessive bureaucracy Inadequate support staff & $\begin{array}{l}\text { Navigate complex work flows Coordinate care across } \\
\text { settings (ex: between rural health post and hospital) } \\
\text { Cultivate relationships with frontline health workers }\end{array}$ \\
\hline
\end{tabular}

informed consent before procedures. Third, they offer doula-like labor support that prevents the neglect and abandonment felt by many patients during hospital delivery. Importantly, doula services in the United States have been shown to reduce cesarean delivery rates [44], which raises an important future research question for our model of the navigators role as advocates. When disrespect and abuse does occur in medical care, care navigators offer emotional support and companionship to the affected woman. In addition, care navigators can perform small interventions to protect patient dignity, such as shielding a patient when she is must undress in an overcrowded hospital without privacy.

The role of our obstetric care navigators, as a bridge between indigenous Maya communities and public hospitals, requires a unique skillset. On one hand, care navigators gain the trust and respect of midwives, patients, and their families, as they are themselves women from indigenous communities and native speakers of Maya Kaqchikel. To function in the medical setting and garner respect from non-indigenous staff, navigators must also be fluent in Spanish, facile with communication technology (including smart phones to document clinical encounters), and possess some formal education. Care navigators also develop strong communication skills, as they must deploy non-confrontational ways to advocate for their patients' needs. We provide formal training in medical interpretation and how to facilitate informed consent discussions between patients and providers. Role-playing exercises help navigators gain motivational interviewing and conflict resolution skills. In addition, bimonthly team meetings also include time for reflection on difficult patient cases, and mental health resources are available for further staff support.

With respect to interactions with traditional midwives, our philosophy of care navigation springs in large part from direct, sustained collaboration with traditional midwives and their feedback as they usually do not feel comfortable accompanying patients to hospitals because they lack many of these aforementioned skills (especially Spanish language fluency and facility with technology), do not understand how to navigate the hospital, and often suffer discrimination. The care navigation model continues to support the role of traditional midwives as trusted health providers and important leaders in Maya communities [45], while providing additional complementary services at the referral level.

We hypothesize that a key feature of our obstetric care navigation model is that it also substantially benefits hospital-level providers by addressing the system deficiencies that fuel disrespectful and abusive care. For example, providers' work becomes more efficient because Mayan language interpreters are on hand. Care navigators can also help overcome some of the frustrations of practicing medicine in a resource-poor facility, such as being able to enable requests for needed medications and laboratory tests that would otherwise go unmet. After hospitalizations, patients continue to receive care navigators' support, 
making them more likely to adhere to treatment plans. Importantly, care navigators do not duplicate services already available within hospitals, but instead fill in gaps in care. They can also extend the capacity of positions that exist but are severely understaffed, such as a provincial referral hospital's sole social worker.

To date, hospital staff have welcomed obstetric care navigators and the services they offer. Prior to implementation of our pilot, we involved heads of maternity services of the health centers and hospitals in Chimaltenango during planning stages and elicited their perspectives on barriers to care for indigenous women, drivers of disrespectful medical care, and specific non-clinical support obstetric care navigators could provide to their medical teams. Their suggestions led to numerous and ongoing program modifications, including use of colored uniforms to distinguish care navigators from providers of medical care in maternity areas. We also introduced care navigators to hospital staff prior to implementation in order to promote collegial relationships.

It is worth highlighting two ways in which our obstetric care navigation approach may differ from existing approaches to respectful maternity care [13, 14]. First, obstetric care navigation is a demand-driven approach that empowers communities to generate their own solutions to disrespectful obstetric care. Both care navigators and traditional midwives are drawn from the communities served by the program and have played an integral role in its conceptualization, and ongoing quality improvement (including participation in biweekly team meetings). While hospital-level interventions may complement the program we describe here, we believe obstetric care navigators are best able to gain trust and adapt to local needs, in no large part because they operate in a complementary fashion at the community level and outside Ministry of Health governance and human resources models.

\section{Uniting respectful maternal care and quality of care}

Disrespectful and abusive care is inseparable from larger concerns about the low quality of maternity care in LMICs. Women and their families have long raised these concerns about public health facilities, which cannot be explained solely by communication barriers and cultural misperceptions. Promoting facility-based delivery without concurrent efforts to improve quality may paradoxically increase maternal mortality. Indeed, within some areas of Guatemala rates of maternal death are higher in hospital as compared to home births with traditional midwives. Simply recommending universal hospital delivery would cause further strain and likely decrease quality further. By guaranteeing emergency services for women who opt for home births, the care navigator model selects only those with complications for facility-based deliveries and allocates scarce hospital resources to the women who face the highest risk of maternal mortality. As such, services can be focally deployed in communities with the highest maternal mortality rates to determine the greatest impact for cost.

Our pilot program includes components explicitly directed at improving quality of care beyond just the obvious interpersonal and communication roles played by the navigator. First, care coordination efforts seek to overcome the disjointed referral chain and reduce loss-tofollow-up. Transportation is provided not only for emergency referrals, but also for outpatient visits to facilitate earlier detection and appropriate care for high-risk pregnancies and for postpartum follow up. Second, the lead physician is in frequent communication with providers in public facilities of the catchment area, working to overcome the limits of existing referral mechanisms. In addition, this physician audits care patients receive and communicates treatment recommendations to public sector physicians. Finally, quality improvement efforts in low-resource settings are often limited by inadequate data collection and analysis infrastructure. However, in our pilot project, all community-level data generated are shared with public facilities to help them better understand out-of-hospital needs and longitudinal patient outcomes. This process is greatly facilitated by the project's use of a centralized electronic medical record.

\section{Conclusions}

While obstetric care navigation alone will not solve the problem of disrespectful and abusive obstetric care, care navigators offer a significant incremental improvement in the experience of maternity care. The collective impact of their interactions with patients and providers has the potential to be transformative. Profound cultural and contextual differences between indigenous patients and non-indigenous providers enable disrespectful behavior on the part of providers and leads to unrealistic patient expectations. Obstetric care navigators facilitate a shared understanding that humanizes patients to providers and vice versa. Care navigators' presence can also play an important role in changing institutional culture, especially when they model labor support techniques and provide passive education on informed consent. In time, these forces may help to break the self-perpetuating cycle of disrespectful and abusive care, leading to improved utilization, patient satisfaction, and maternal outcomes, as well as provider engagement in caring for indigenous populations.

Currently, we are in the process of collecting outcomes data on the objective success of our pilot, which will conclude in April 2018. This includes careful assessment of improvements in obstetrical referral success rates, referral times, and adherence to medical treatment. We are also closely tracking patient satisfaction and experience metrics 
along with qualitative assessment of the program's potential impact. Following completion of this demonstration project we hope to share our results and partner with other communities, NGOs, and governments to disseminate the model. Rigorous implementation science methods will be needed to adapt the model to local needs, engage communities and stakeholders, and monitor success. We invite implementers and funders alike to join us and others in investigating the role obstetric care navigation and other patient accompaniment models can play in the development of community-driven solutions which promote respectful maternity care.

\section{Abbreviations}

LMIC: low and middle-income countries; MHA: Maya Health Alliance

\section{Acknowledgements}

We would like to thank the traditional midwives, care navigators, patients, and staff of Hospital Nacional de Chimaltenango (especially Dra. Ligia Liquidano) who are helping MHA to develop this innovative model. We would also like to acknowledge inspiration from the Birth Sister program innovated by the professional midwives at Boston Medical Center which pairs high-risk mothers with limited resources to a trained "sister-like" support from prenatal care through postpartum visits.

\section{Funding}

This project is supported by Canada Grand Challenges Stars in Maternal and Child Health (R-ST-POC-1707-06554) to KA and PR.

\section{Availability of data and materials}

Not applicable.

\section{Authors' contributions}

$\mathrm{KA}, \mathrm{BM}, \mathrm{MJ}, \mathrm{EC}$, and $\mathrm{YJ}$ brainstormed the foundational ideas of the manuscript. KA drafted the manuscript with critical input from AC and PR. All authors approved the final version. All authors read and approved the final manuscript.

\section{Ethics approval and consent to participate}

Not applicable.

\section{Consent for publication}

Not applicable.

\section{Competing interests}

The authors declare that they have no competing interests.

\section{Publisher's Note}

Springer Nature remains neutral with regard to jurisdictional claims in published maps and institutional affiliations.

\section{Author details}

'Wuqu' Kawoq | Maya Health Alliance 2 Calle 5-43, Zona 1, Santiago Sacatepéquez, Guatemala. ${ }^{2}$ Division of Women's Health, Department of Medicine, Brigham and Women's Hospital, 75 Francis Street, Boston, MA 02115, USA. ${ }^{3}$ Department of Emergency Medicine, Massachusetts General Hospital, 55 Fruit Street, Boston, MA 02114, USA. ${ }^{4}$ Division of Global Health Equity, Brigham and Women's Hospital, 75 Francis Street, Boston, MA 02115, USA.

Received: 24 August 2017 Accepted: 2 November 2017

Published online: 13 November 2017

\section{References}

1. WHO, UNICEF, UNFPA, World Bank Group, UNPD. Trends in materna mortality 1990 to 2015: estimates by WHO, UNICEF, UNFPA, World Bank Group and the United Nations population division. Geneva: World Health Organization; 2015
2. World Health Organization. Recommendation on antenatal care for positive pregnancy experience. Geneva: World Health Organization; 2016.

3. Afulani PA, Moyer C. Explaining disparities in use of skilled birth attendants in developing countries: a conceptual framework. PLoS One. 2016;11: e0154110. https://doi.org/10.1371/journal.pone.0154110.

4. World Health Organization. The prevention and elimination of disrespect and abuse during facility-based childbirth. Geneva: World Health Organization; 2015. doi:WHO/RHR/14.23

5. Bohren MA, Hunter EC, Munthe-Kaas HM, Souza JP, Vogel JP, Gülmezoglu AM. Facilitators and barriers to facility-based delivery in low- and middle-income countries: a qualitative evidence synthesis. Reprod Health. 2014;11:71. https:/ doi.org/10.1186/1742-4755-11-71.

6. Bowser D, Hill K. Exploring evidence for disrespect and abuse in facilitybased childbirth: report of a landscape analysis. 2010. http://www. tractionproject.org/sites/default/files/Respectful_Care_at_Birth_9-20-101_ Final.pdf. Accessed 23 Aug 2017.

7. Abuya T, Warren CE, Miller N, Njuki R, Ndwiga C, Maranga A, et al. Exploring the prevalence of disrespect and abuse during childbirth in Kenya. PLoS One. 2015;10(4):e0123606. https://doi.org/10.1371/journal.pone.0123606.

8. Rosen HE, Lynam PF, Carr C, Reis V, Ricca J, Bazant ES, et al. Direct observation of respectful maternity care in five countries: a cross-sectional study of health facilities in east and southern Africa. BMC Pregnancy Childbirth. 2015;15:306. https://doi.org/10.1186/s12884-015-0728-4.

9. United Nations Office of the High Commissioner for Human Rights. Committee on economic, social, and cultural rights general comment number 14: the right to the highest attainable standard of health (article 12). New York: United Nations; 2000.

10. Sadler M, Santos MJ, Ruiz-Berdún D, Rojas GL, Skoko E, Gillen P, et al. Moving beyond disrespect and abuse: addressing the structural dimensions of obstetric violence. Reprod Health Matters. 2016;24:47-55. https://doi.org/ 10.1016/j.rhm.2016.04.002.

11. Warren CE, Njue R, Ndwiga C, Abuya T. Manifestations and drivers of mistreatment of women during childbirth in Kenya: implications for measurement and developing interventions. BMC Pregnancy Childbirth 2017;17:102. https://doi.org/10.1186/s12884-017-1288-6.

12. Freedman LP. Kruk ME. Disrespect and abuse of women in childbirth: challenging the global quality and accountability agendas. Lancet. 2014;384 e42-4. https://doi.org/10.1016/S0140-6736(14)60859-X.

13. Ratcliffe HL, Sando D, Lyatuu GW, Emil F, Mwanyika-Sando M, Chalamilla G, et al. Mitigating disrespect and abuse during childbirth in Tanzania: an exploratory study of the effects of two facility-based interventions in a large public hospital. Reprod Health. 2016;13:79. https://doi.org/10.1186/s12978-016-0187-z

14. Abuya T, Ndwiga C, Ritter J, Kanya L, Bellows B, Binkin N, et al. The effect of a multi-component intervention on disrespect and abuse during childbirth in Kenya. BMC Pregnancy Childbirth. 2015;15:224. https://doi.org/10.1186/ s12884-015-0645-6.

15. Holt K, Caglia JM, Peca E, Sherry JM, Langer A. A call for collaboration on respectful, person-centered health care in family planning and maternal health. Reprod Health. 2017;14:20. https://doi.org/10.1186/s12978-017-0280-y.

16. Peca E, Delgado H, Cobo MB. Using qualitative methods to improve health system responsiveness in the western highlands of Guatemala. Presentation at the Third Global Symposium On Health SystemsResearch: 30 September3 October 2014; Cape Town. http://www.tractionproject.org/resources/ access-skilled-care-respectful-maternal-care/using-qualitative-methodsimprove-health. Accessed 22 Aug 2017.

17. Ministerio de Salud Pública y Asistencia Social, Secretaria de Planificacion y Programacion de la Presidencia. Estudio nacional de mortalidad materna 2007. 2011. http://sigsa.mspas.gob.gt/sigsa/index.php/bases-de-datos/2estudio-de-muerte-materna/13-estudio-nacional-de-mortalidad-materna2007-general. Accessed 22 Aug 2017.

18. Ministerio de Salud Pública y Asistencia Social. Encuesta nacional de salud materno infantil 2014-2015: Informe Final. Guatemala City: Ministerio de Salud Pública y Asistencia Social; 2017.

19. Central Intelligence Agency. The world Factbook: Guatemala. 2014. https:// www.cia.gov/library/publications/the-world-factbook/geos/gt.html. Accessed 22 Aug 2017.

20. Comisión para el Esclarecimiento Histórico. Guatemala: memoria del silencio. Guatemala City: Comisión para el Esclarecimiento Histórico; 1999.

21. Congreso de la República de Guatemala. Congreso de la República de Guatemala Decreto No 90-97. Guatemala City: Congreso de la República de Guatemala; 1997. 
22. Pan-American Health Organization. Health in the Americas. Washington, D.C. Pan-American Health Organization; 2012.

23. Avila C, Bright R, Gutierrez J, Hoadley K, Coite M, Romero N, et al. Guatemala health system assessment, august 2015. Bethesda, M.D.: Health Finance and Governance Project, Abt Associates Inc.; 2015.

24. Tzian L. Mayas y ladinos en cifras: el caso de Guatemala. Editorial Cholsamaj: Guatemala City, Guatemala; 1994.

25. Chary A, Díaz AK, Henderson B, Rohloff $P$. The changing role of indigenous lay midwives in Guatemala : new frameworks for analysis. Midwifery. 2013; 29:852-8.

26. Berry NS. Kaqchikel midwives, home births, and emergency obstetric referrals in Guatemala: contextualizing the choice to stay at home. Soc Sci Med. 2006;62:1958-69.

27. Colombara DV, Hernández B, Schaefer A, Zyznieuski N, Bryant MF, Desai SS, et al. Institutional delivery and satisfaction among indigenous and poor women in Guatemala, Mexico, and Panama. PLoS One. 2016;11:e0154388. https://doi.org/10.1371/journal.pone.0154388.

28. Martinez B, Hall-Clifford R, Coyote E, Stroux L, Valderrama CE, Aaron C, et al. Agile development of a smartphone app for perinatal monitoring in a resource-constrained setting. J Health Inform in Dev Countries. 2017;11(1):158.

29. Stroux L, Martinez B, Coyote Ixen E, King N, Hall-Clifford R, Rohloff P, et al. An mHealth monitoring system for traditional birth attendant-led antenatal risk assessment in rural Guatemala. J Med Eng Technol. 2016:40:356-71. https://doi.org/10.1080/03091902.2016.1223196.

30. Freeman HP. The origin, evolution, and principles of patient navigation. Cancer Epidemiol Biomark Prev. 2012;21:1614-7.

31. Natale-Pereira A, Enard KR, Nevarez $L$, Jones $L A$. The role of patient navigators in eliminating health disparities. Cancer. 2011;117:3541-50. https://doi.org/10.1002/cncr.26264.

32. Franke MF, Kaigamba F, Socci AR, Hakizamungu M, Patel A, Bagiruwigize $E$, et al. Improved retention associated with community-based accompaniment for antiretroviral therapy delivery in rural Rwanda. Clin Infect Dis. 2013;56:1319-26. https://doi.org/10.1093/cid/cis1193.

33. Mukherjee JS, Barry D, Weatherford RD, Desai IK, Farmer PE. Communitybased ART programs: sustaining adherence and follow-up. Curr HIV/AIDS Rep. 2016;13:359-66. https://doi.org/10.1007/s11904-016-0335-7.

34. World Health Organization. Companion handbook to the World Health Organization guidelines for the Pprogrammatic management of drugresistance tuberculosis. Geneva: World Health Organization; 2014.

35. Munyaneza F, Ntaganira J, Nyirazinyoye L, Birru E, Nisingizwe MP, Gupta N, et al. Community-based accompaniment and the impact of distance for HIV patients newly initiated on antiretroviral therapy: early outcomes and clinic visit adherence in rural Rwanda. AIDS Behav. 2016. https://doi.org/10.1007/ s10461-016-1658-5. [Epub ahead of print].

36. Moy B, Chabner BA. Patient navigator programs, cancer disparities, and the patient protection and affordable care act. Oncologist. 2011;16:926-9. https://doi.org/10.1634/theoncologist.2011-0140.

37. Wang ML, Gallivan L, Lemon SC, Borg A, Ramirez J, Figueroa B, et al. Navigating to health: evaluation of a community health center patient navigation program. Prev Med Reports. 2015;2:664-8. https://doi.org/10. 1016/j.pmedr.2015.08.002.

38. Chary A, Flood D, Moore J, King N, Austad K, Martinez B, et al. Navigating bureaucracy: accompanying indigenous Maya patients with complex health care needs in Guatemala. Human Organization. 2016;75:305-14.

39. Zamorano AS, Barnoya J, Gharzouzi E, Chrisman RC. Compliance after treatment is a major barrier to the optimal treatment of cervical cancer in Guatemala. Rancho Mirage: Western Association of Gynecologic Oncologists Annual Meeting; 2017. June 14-17.

40. Lassi ZS, Bhutta ZA. Community-based intervention packages for reducing maternal and neonatal morbidity and mortality and improving neonatal outcomes. Cochrane Database Syst Rev. 2010;11:CD007754. https://doi.org/ 10.1002/14651858.CD007754.pub3.Copyright.

41. Nahar S, Banu M, Nasreen HE. Women-focused development intervention reduces delays in accessing emergency obstetric care in urban slums in Bangladesh: a cross-sectional study. BMC Pregnancy Childbirth. 2011;11:11. https://doi.org/10.1186/1471-2393-11-11.

42. Jolly SP, Rahman M, Afsana K, Yunus FM, Chowdhury AMR. Evaluation of maternal health service indicators in urban slum of Bangladesh. PLoS One. 2016;11:1-19.

43. Provost LP, Murray $S$. The health care data guide: learning from data for improvement. J Wiley \& Sons: Hoboken; 2011.
44. Bohren MA, Hofmey GJ, Sakala C, Fukuzawa RK, Cuthbert A. Continuous support for women during childbirth. Cochrane Database Syst Rev. 2017; https://doi.org/10.1002/14651858.CD003766.pub6.

45. Maupin JN. Remaking the Guatemalan midwife: health care reform and midwifery training programs in highland Guatemala. Med Anthropol. 2008; 27:353-82.

\section{Submit your next manuscript to BioMed Central and we will help you at every step:}

- We accept pre-submission inquiries

- Our selector tool helps you to find the most relevant journal

- We provide round the clock customer support

- Convenient online submission

- Thorough peer review

- Inclusion in PubMed and all major indexing services

- Maximum visibility for your research

Submit your manuscript at www.biomedcentral.com/submit
Biomed Central 